\title{
Synthesis and Nonlinear Optical Properties of Novel Polyester with 2,3-Dioxybenzylidenecyanoacetate
}

\author{
Han-Na Jang, Hyo Jin No, and Ju-Yeon Lee \\ Institute of Basic Science, Department of Chemistrv, Inje Eniversitv, Gimhae 621-749, Korea \\ E-mail: chemljwinje ack \\ Recerved Atgust 26, 2008, Accepted January 28, 2009
}

Key Words: Nonlinear optics. Polyester. Thermal stability, Second harmonic generation. Relaxation of dipole alignment

Nonlinear optical (NLO) poly mers received a great attention in recent years because of their potential applications in the field of electro-optic devices. ${ }^{1 \cdot 3}$ A potential NLO poly mer has to be mechanically very strong and thermally stable with a high glass-transition temperature $\left(T_{g}\right)$. In the developments of $\mathrm{NLO}$ polymers for electro-optic device applications. stabilization of electrically induced dipole alignment is one of important criteria; in this context, two approaches have been proposed to minimize the randomization of dipole alignment namely the use cross-linking method ${ }^{4-3}$ and the utilization of ligh $\dot{T}_{z}$ polymers such as polyimides. ${ }^{8}$ Various polyesters with NLO-chromophores in the main chain ${ }^{9}$ or in side chain ${ }^{\text {di }}$ have been prepared and their properties studied. In general. main-chain NLO polymers have good thermal stability of dipole alignments. but they often do not dissolve in organic solvents. and their intractability make them unusable to fabricate stable films. Side-chain NLO polymer sy'stems have the advantages such as good solubility, homogeneity and high loading level of NLO chromophores relative to the main-chain sy stems. but they often suffer from poor stability of dipole alignments at high temperatures. Recently we have prepared novel polyesters containing dioxynitrostilbene $\mathrm{e}^{11-1-2}$ or 2,3-dionybenzylidenemalononitrile ${ }^{13}$ as NLO chromophores. The resulting polymers exhibited enhanced thermal stability of second hamonic generation (SHG), which stemuned from the stabilization of dipole alignment of the NLO chromophore. In this work we prepared another novel polyester containing 2.3-dionybenzylidenecyanoacetate groups as NLO-chromophores. We selected the latter because they have a large dipole moment and are rather easy to synthesize. Furthenmore. 2,3-dioxyben-

(a)

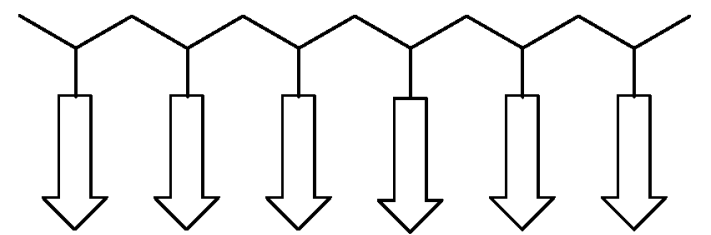

(b)

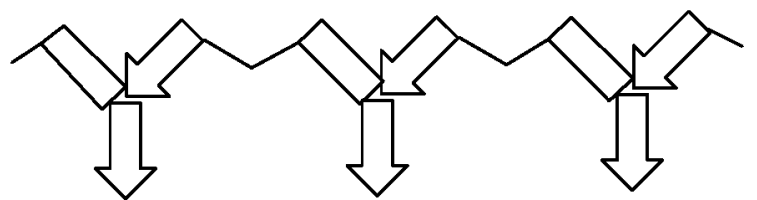

Figure 1. (a) Side-chain NLO polymers and (b) Y-type NLO polymers. zylidenecyanoacetate group constitutes novel Y-type NLO polyester (Fig. lb), and this Y-ty'pe NLO polyester has not yet been reported in the literature. Thus, we synthesized a new type of NLO polyester, in which the pendant NLO chromophores are components of the polymer backbone. This mid-type NLO polymer is expected to have the advantages of both main-chain and side-chain NLO polymers namely stable dipole alignment and good solubility. After confirming the structure of the resulting polymer we investigated its properties such as solubility. $T_{\mathrm{g}}$. themtal stability. second harmonic generation (SHG) activity and relaxation of dipole aligument. We now report the results of the initial phase of the work.

\section{Results and Discussion}

2.3-Di-(2'-viny loxyethoxy)benzaldehyde (1) was prepared by the reaction of 2-chloroethyl vinyl ether with 2.3-dihydroxybenaldehyde. Methyl 2.3-di-(2'-viny loxyethoxy)benzylidenecyanoacetate (2) was prepared by the condensation reaction of compound 1 with methyl cyanoacetate. Compound 2 was hydrolyzed to yield acetaldelyde and diol 3. Monomer 3 was condensed with terephthaloyl chloride in a dry DMF solvent to y ield polyester 4 containing the NLO-chromophore 2.3-dioxybenzylidenecyanoacetate group. The synthetic route for polyester + is presented in Scheme 1 . The polymerization yield was $90 \%$. The chemical structure of the resulting poly mer was confirmed by ${ }^{1} \mathrm{H} N \mathrm{NM}$. R spectra. and elemental analysis. Elemental analysis results fit the poly mer structure. ${ }^{~} \mathrm{H}$ NMR spectrum of the polymer showed a signal broadening due to polymerization, but the chemical slifts are consistent with the proposed polymer structure. The IR spectrum of the same polymer shows a strong carbonyl peak near $1722 \mathrm{cml}^{-1}$ indicating the presence of ester bond. The same polymer sample also shows a strong absorption peak near $2224 \mathrm{~cm}^{-1}$ and $1605 \mathrm{~cm}^{-1}$ due to the nitrile and olefin groups, respectively. These results are consistent with the proposed structure. indicating that the NLO-cluromophore remained intact during the polymerization. The molecular weights were determined by GPC using polystyrene as the standard and THF as an eluent. The number average molecular weight $\left(M_{1}\right)$ of the polymer + was determined to be $16.200\left(M_{\mathrm{w}} / \mathrm{M}_{\mathrm{n}}=1.94\right)$. The structural feature of this polymer is that it has pendant NLO chromophores. which are parts of the polymer main chains. Thus the resulting polymer $t$ is a mid type of side-chain and main-chain NLO polymer, 

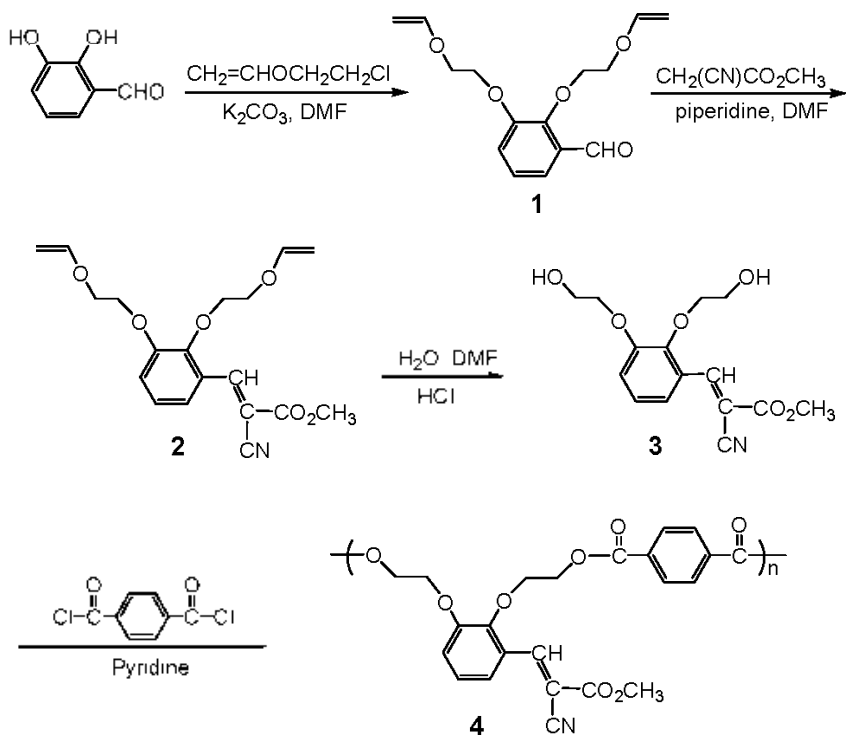

Scheme 1. Synthetic sehene and structure of polymer 4 .

and is expected to have both of their merits. The polymer 4 is soluble in common solvents such as acetone, DMF, and DMSO, but is not soluble in methanol and diethyl ether. The inherent viscosity was $0.28 \mathrm{dI} / \mathrm{g}$. Polymer 4 showed strong absorption near $313 \mathrm{~nm}$ by the $\mathrm{NLO}$-chromophore 2,3-dioxybenz:lidenecyanoacetate group. We now have well defined polyester (4) and investigate its properties.

The thermal behavior of the polymer was investigated by thermogravimetric analysis (TCiA) and differential scanning calorimeter (DSC) to determine the thermal degradation pattern and glass transition temperature $\left(T_{g}\right)$. DSC thermogram of polymer 4 is presented in Fig. 2. Poly mer 4 showed a thermal stability up to $260^{\circ} \mathrm{C}$ according to its $\mathrm{IIG}^{\mathrm{G}} \mathrm{A}$ thermogram. The $T_{g}$ value of the polymer 4 measured by DSC were around 100 " $\mathrm{C}$. This $T_{\mathrm{g}}$ value is somew hat higher than that of the polyester containing 2,3-dioxybenzy lidenemalononitrile. ${ }^{13}$ The $T G \Lambda$ and DSC studies showed that the decomposition temperature of the polyester 4 was higher than the contesponding $T_{g}$. This indicates that high-temperalure poling for a short $1 \mathrm{~cm}$ is feasible without damaging the N.O chromophore.

The NI.O properties ol poly mer 4 were studied by the SI IG method. lo induce noncentrosymmetric polar otder, the spin-coated polymer film was cornna-poled. The poling was contitmed by UV-Vis spectra. After electric poling, the dipole moments of the NI. ()-chromophores were aligned and IJV-Vis spectrum of polymer 4 exhibited a decrease in absorption due to birefringence. From the absorbance change, the order parameter of the poled film could be estimated. which is related to the poling efficiency. The estimated order parameter value $\Phi$ of polymer 4 was equal to 0.18 for polymer $4\left(\Phi=1-A_{1} / A_{0}\right.$. where $\Lambda_{0}$ and $\Lambda_{1}$ are the absorbanees of the polymer lilm before and after poling). For the purpose of investigating surlace morphology of polymer films, domain struetures of NLO-chromophores for the thin-film samples were obtained using atomic foree microscopy (AFM). Fig. 3 shows AFM seans of the spin-eoaled film before and alter poling polymer 4. AFM inages show that the surface of the film sample is tlat

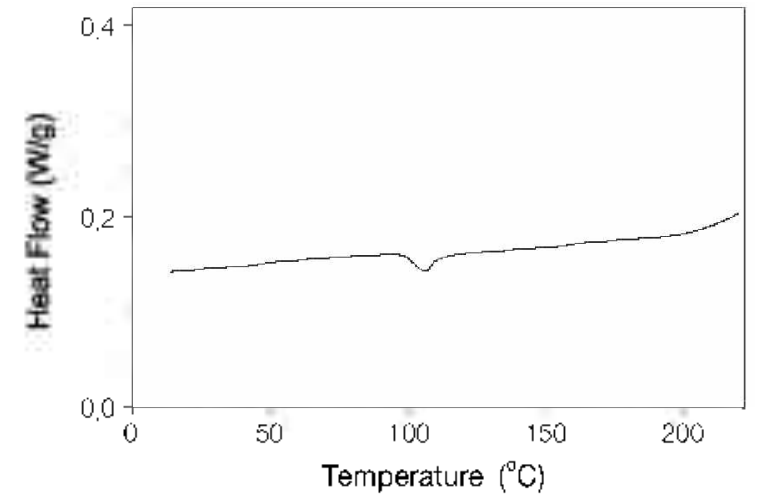

liggwe 2. DSC thermogran of polymer 4 at a heating rate of $10^{\circ} \mathrm{C}$ min under nitrogen.

(a)

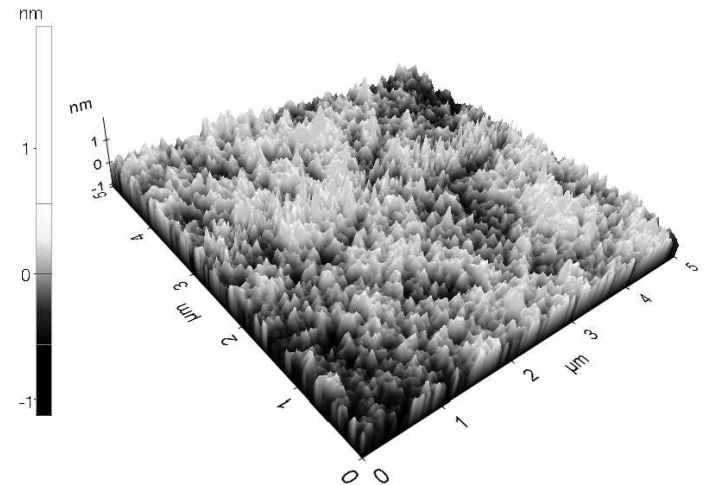

(b)

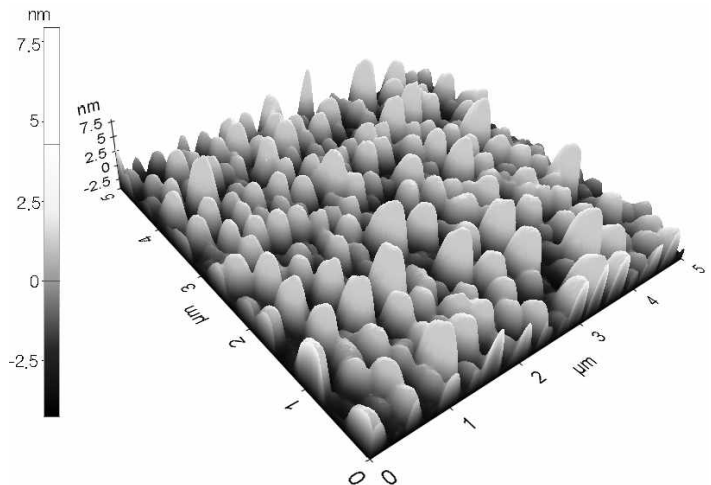

Higure 3. AFM images of spiti-coated lilm of polymer 4 : (a) belore corona-poling: (b) alter corona-poling.

and clean belore poling (see liig. 3a). Howerer, this good quality film was dramatically changed alter poling, resulting in numerous hills and valleys in the surlace structure, which means that the NLO-chromophores are aligned the poling direction as shown in Fig. 3b. The refractive index of the sample was measured by the optical transmission technique. ${ }^{\text {t+ }}$ $\mathrm{SHC}$ measurements were performed at a fundamental wavelength of 1064 non using a mode looked Nd-YAG laser. NTO properties of polymer 4 are summarized in Table 1 . In order to detemine the microscopic second-order susceptibility of the polvmer, the angular $\mathrm{SHG}$ dependence was recorded. Fig. 4 shows the angular dependence of $\mathrm{SHG}$ signal in a poled polvmer 4 . The $\$ H G$ values were compared with those obtained from a $Y$-cut quattz plate. To calculate the $d_{3 z}$ and $d_{33}$ values, both $s$-polarized and $p$-polarized IR laser were directed to the 
Table 1. Nonlinear Optical Propertics of Polvmer 4

\begin{tabular}{|c|c|c|c|c|c|c|}
\hline Polymer & $\begin{array}{l}\lambda_{\text {tinas }}{ }^{\prime \prime} \\
(\mathrm{nm})\end{array}$ & $\begin{array}{l}d 3^{b} \\
(\mathrm{esu})\end{array}$ & $\Phi^{r}$ & $\begin{array}{l}d_{31}^{b} \\
(\mathrm{esu})\end{array}$ & $\begin{array}{c}\text { film thickness } \\
(\mu \mathrm{m})\end{array}$ & $n$ \\
\hline 4 & 313 & $(3.47+0.09) \quad 10^{-9}$ & 0.18 & $(1.35+0.04) \quad 10^{-9}$ & 0.54 & $\begin{array}{l}\mathrm{n}_{1}-1.63 \\
\mathrm{n} \geq-1.71\end{array}$ \\
\hline
\end{tabular}

${ }^{n}$ Polymer film. "SH IG coellicients ( $\left.d_{33}\right)$ were derived from the analysis of measured Maker-lringes. ${ }^{15}$ "Order parameler (D) - $1-A_{1} \cdot A_{\|_{4}}$ where $A_{4}$ and $A_{1}$ are the absorbances of the polvmer film betore and after corona poling. respectively. "Film thickness was determined by the optical transmission technique."

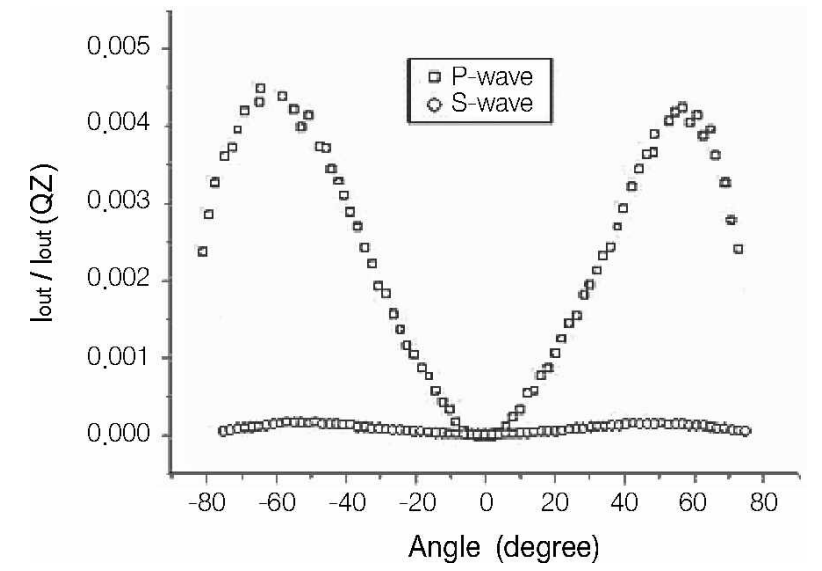

Figure 4. Angular dependence ol SHG signal in a poled lilm ol polymer 4.

samples and recorded. SHG coefficients were derived from the analysis of measured Maker-tringes with Pascal fitting program aceording to the literature procedure. ${ }^{15}$ The values of $d_{13}$ and $d_{d I}$ for polymer 4 were $(3.47 \pm 0.09) \times 10^{-3}$ and $(1.35$ $\pm 0.04) \times 10^{-3}$ esu, respectively. These values are similar with those for the polyester containing 2,3-dioxybenzylidenemalononitrile group. ${ }^{17}$ Since the second harnonic wavelength was at $532 \mathrm{tmm}$, which is not in the absorptive region of the resulting polyesters, there was not resonant contribution to this $d_{3 z}$ value

To evaluate the high-temperature stability of the polymers, we studied the temporal stability of the SI IG signal. In Fig. 5 , we present the dynamic thermal stability study of the NLO activity of the film 4 . To investigate the real time NLO decay of the SIIG signal of the poled polymer tilms as a tunction of temperature, in situ $\mathrm{SHG}$ measurements were performed at a heating rale of $3{ }^{\circ} \mathrm{C} / \mathrm{min}$ from $30^{\circ} \mathrm{C} 10140^{\circ} \mathrm{C}$. The polymer thin film exhibited a thermal stability up to $T_{g}$ and no signilicant SIIG decay was observed below $100{ }^{\circ} \mathrm{C}$. as shown in Fig. 6. This SI IG themal stability is somewhat higher than that of the polyester containing 2,3-dioxybenzylidenemalononitrile group. ${ }^{1.3}$ In general, side chain NLO polymers lose thermal stability of dipole aligmment below $T_{g}$. Stabilization of dipole alignment is a characteristic of main chain NI.O polymers. The enhanced thermal stability of second harmonic generation of polymer 4 is due to the stabilization of dipole alignment of $\mathrm{NL}$, O chromophore, which stems irom the partial main chain character of the polymer struclure. Thus, we obtained another new NI.() polyester having both the merits of main-chain and side-chain NLO polymers namely stable dipole alignument and good solubility.

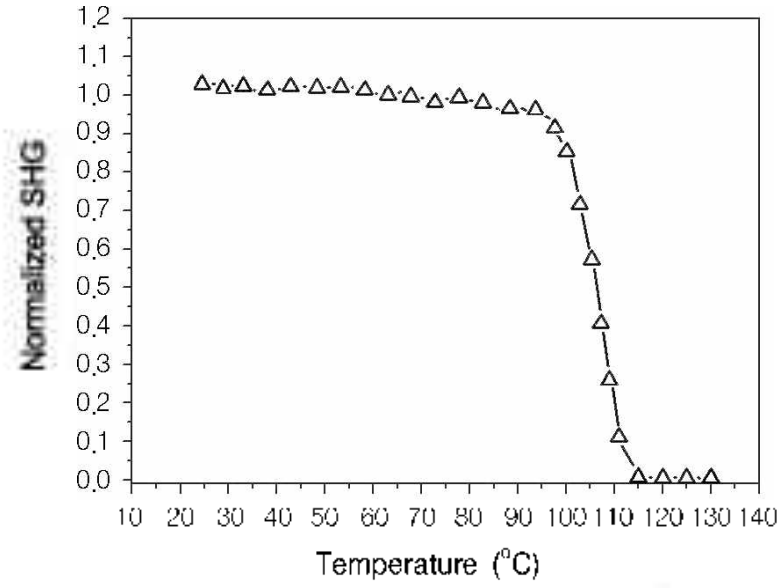

Figure 5. Normalized $\mathrm{SHG}$ signal of polymer 4 as a lunction of temperature at a lieating rate of 3 "Cimin.

\section{Expcrimental Section}

Materials. The reagent grade chemicals were purchased from Aldrich and purified by either distillation or reerystallization before use. 2,3-Dihydroxybenzaldehyde, 2-chloroethy'1 vinyl ether, and tetrahydroluran (TI IF) were used as received. lerephthaloyl chloride (TPC) was purified by sublimation under vacuum. Methyl cyanoacetate was distilled under reduced pressure. Piperidine was treated with potassium hydroxide and then distilled over batium oxide to renove trace amounts of water. $N$, $X$-Dimelhylformanide (DMT) was puriticd by drying with anhy drous calcium sulfate, followed by distillation under reduced pressure.

Measurements. IR spectra were taken on a Shimadzu lFI IR-8201PC infrared spectrophotometer. ${ }^{1} \mathrm{H}$ NMR spectra were obtained on a Varian $300 \mathrm{MH}$ \% NMR spectrometer. UV-Vis absorption spectra were measured on a Shimadzu UV-310os spectrophotomeler. Flemental analyses were perlorned using a Perkin-F:Imer 2400 CIIN elemental analy/er. The glass transition temperatures $\left(I_{p}\right)$ were measured on a TA 2920 diflerential scanning calorimeter in a nitrogen atmosphere. IAQ50 thermogravinetric analyzer with a heating rate of 10 "C/min up to $800^{\circ} \mathrm{C}$ was used for the thermal degradation study of polymers under nitrogen. 'the number average molecular weight $\left(H_{11}\right)$ and weight average molecular weight $\left(H_{w}\right)$ of the polymers were estimated by gel permeation chromatography (GPC) (columns Styragel HR5F,4F; solvent THF). Atomic foree nicroseopy $(\Lambda \mathrm{l} \cdot \mathrm{M})$ images were recorded with a Park Science Instrument Autoprobe $C P$, operated in a contact mode, 
which measures topography. Viscosity values were obtained by using a Cannon-Fenske viscometer.

Film Preparation and SHG Measurements. The refractive index of the sample was measured by the optical transmission technique. ${ }^{14}$ The transmittance of thin film includes on the information of the thickness. refractive index and extinction coefficient of that. Thus. we determined these parameters by analyzing the transmittance. Second harmonic generation (SHG) measurement was carried out one day after poling. The Maker Fringe pattern was obtained from measuring the $\mathrm{SHG}$ signal at $0.5^{\circ}$ intervals using a rotation stage. SHG coefficients $\left(d_{33}\right)$ were derived from the analy'sis of measured Maker-fringes. ${ }^{15}$

Preparation of 2,3-(2'-Vinyloxyethoxy)benzaldehyde (1). 2.3-Dihydroxybenzaldehyde $(13.8 \mathrm{~g} .0 .10 \mathrm{~mol})$, anhydrous potassium carbonate ( $36 \mathrm{~g}, 0.36 \mathrm{~mol})$, and 2-chloroethyl vinyl ether (26.6 g. $0.25 \mathrm{~mol}$ ) were dissolved in $200 \mathrm{~mL}$ of dry DMF under nitrogen. The mixture was refluxed in an oil bath kept at 100 " $\mathrm{C}$ for $40 \mathrm{~h}$ under nitrogen. The resulting solution was cooled to room temperature. diluted with $300 \mathrm{~mL}$ of water. and extracted with $300 \mathrm{~mL}$ of diethyl ether three times. The organic layer was washed with saturated aqueous sodium chloride solution, and dried with anhydrous magnesium sulfate. Rotary evaporation of diethyl ether gave cnide product. which was recry stallized from l-butanol yielded $24.5 \mathrm{~g}$ ( $88 \%$ yield) of pure product $1 . \mathrm{Mp}=48-50^{\circ} \mathrm{C}$. ${ }^{1} \mathrm{H} \mathrm{NMR}\left(\mathrm{CDCl}_{3}\right)$ ò $3.95-4.47$ (m. 12H. $2 \mathrm{CH}_{2}=, 2-\mathrm{O}-\mathrm{CH}_{2}-\mathrm{CH}_{2}-\mathrm{O}-$ ) , 6.44-6.57 (m, 2H, 2 =CH-O-). 7.09-7.19 (m. 2H. aromatic). 7.42-7.48 (m. lH. aromatic) 10.48 (s. lH -CHO). IR (KBr) 3098, 3076 $(\mathrm{w} .=\mathrm{C}-\mathrm{H}), 2953.2883(\mathrm{~s}, \mathrm{C}-\mathrm{H}), 1682(\mathrm{vs}, \mathrm{C}=\mathrm{O}), 1618$ (vs. $\mathrm{C}=\mathrm{C}) \mathrm{cm}^{-1}$

Preparation of Methyl 2,3-Di-(2'-vinyloxyethoxy)benzylidenecyanoacetate (2). Piperidine $(0.043 \mathrm{~g} .0 .5 \mathrm{mmol})$ was added to a solution of $1(2.78 \mathrm{~g} .10 \mathrm{mmol})$ and methyl cyanoacetate (1.98 g. $20 \mathrm{mmol}$ ) in $30 \mathrm{~mL}$ of DMF with stirring at room temperature under nitrogen. After stirring for $10 \mathrm{~h}$ at room temperature, the reaction mixture was diluted with $\mathbf{5 0}$ $\mathrm{mL}$ of water. and extracted with $80 \mathrm{~mL}$ of diethyl ether three times. The organic layer was dried with anhydrous magnesium sulfate. Rotary evaporation of diethyl ether gave crude product, which was recrystallized from l-butanol yielded $2.87 \mathrm{~g}(80 \%$ vield) of pure product $2 . \mathrm{Mp}=53.55^{\circ} \mathrm{C}$. $\mathrm{H} \mathrm{NMR}\left(\mathrm{CDCl}_{3}\right)$ o 3.92 (s. $3 \mathrm{H},-\mathrm{CO}_{2} \mathrm{CH}_{3}$ ). $3.98-4.43$ (m, 12H. $2 \mathrm{CH}_{2}=.2$ $-\mathrm{O}-\mathrm{CH}_{2}-\mathrm{CH}_{2}-\mathrm{O}-$ ), 6.46-6.59 (m. 2H, 2 =CH-O-), 7.08-7.19 (m. $2 \mathrm{H}$, aromatic) $7.90-7.96$ (d. $1 \mathrm{H}$, aromatic) $8.86(\mathrm{~s}, 1 \mathrm{H}$. benzylic). IR (KBr) $30+7(\mathrm{w},=\mathrm{C}-\mathrm{H}) .29+1,2856(\mathrm{~m} . \mathrm{C}-\mathrm{H})$. 2222 (s. CN). 1728 (vs, C=O). 1618. 1591 (vs. C=C) $\mathrm{cm}^{-1}$. Anal. Calcd for $\mathrm{C}_{19} \mathrm{H}_{21} \mathrm{NO}_{6}$ : C. 63.50, H. 5.89 , N. 3.90 . Found: C. 63.59; H, 5.95: N, 3.84 .

Preparation of Methyl 2,3-Di-(2'-hydroxyethoxy)benzylidenecyanoacetate (3). Aqueous hydrochloric acid (1.5 M. 30 $\mathrm{mL}$ ) was slowly added to a solution of $2(3.59 \mathrm{~g}, 0.01 \mathrm{~mol}) \mathrm{in}$ $30 \mathrm{~mL}$ of dry DMF with stiming under nitrogen at $0^{\circ} \mathrm{C}$. The mixture was stirred at $0^{\circ} \mathrm{C}$ for $12 \mathrm{~h}$ under nitrogen. The resulting solution was filtered and washed with to give $2.61 \mathrm{~g}$ $\left(85 \%\right.$ yield) of 3. Mp $=124-126{ }^{\circ} \mathrm{C} .{ }^{1} \mathrm{H}$ NMR (DMSO- $\left.d_{\theta}\right) \delta$ 3.58 (m, $\left.2 \mathrm{H},-\mathrm{CH}_{2}-\mathrm{O}-\right), 3.75$ (m. $2 \mathrm{H}_{3}-\mathrm{CH}_{2}-\mathrm{O}-$ ). 3.83 (s. $3 \mathrm{H}$. $\left.\mathrm{CO}_{2} \mathrm{CH}_{2}\right) .4 .05$ (t, 2H. Ph-O-CHz- $)$. 4.16 (t. $\left.2 \mathrm{H} .2 \mathrm{Ph}-\mathrm{O}-\mathrm{CH}_{2}-\right)$. 4.81 (t. $1 \mathrm{H} .-\mathrm{OH}) .4 .89$ (t, $1 \mathrm{H} .-\mathrm{OH}), 7.21$ (t. $1 \mathrm{H}$, aromatic), 7.32 (d. IH. aromatic). 7.72 (d. IH. aromatic). 8.82 (s. $1 \mathrm{H}$. -Ph-CH=). IR (KBr) 3318, 3219 (s. O-H). 2928.2876 (m, $\mathrm{C}-\mathrm{H}$ ), 2225 (m, CN). 1724 (vs. $\mathrm{C}=\mathrm{O}), 1612$ (vs, $\mathrm{C}=\mathrm{C}$ ) $\mathrm{cm}^{-1}$.

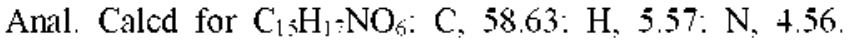
Found: C. 58.72 H. $5.65:$ N. 4.64

Synthesis of Polyester 4 . A representative polycondensation procedure was as follows: Terephthaloyl chloride $(2.03$ g. $0.01 \mathrm{~mol}$ ) and diol $3(3.07 \mathrm{~g} .0 .01 \mathrm{~mol})$ were disolved in 30 $\mathrm{mL}$ of anhydrous pyridine under nitrogen. The resulting solution was refluxed in an oil bath kept at $80^{\circ} \mathrm{C}$ under a nitrogen atmosphere. After heating $12 \mathrm{~h}$ with stirring the resulting poly merization solution was poured into $400 \mathrm{~mL}$ of methanol. The precipitated polymer was collected and reprecipitated from DMSO into methanol. The polymer was further purified by extraction in a Soxhlet extractor with diethyl ether and dried under vacuum, yielding $3.93 \mathrm{~g}(90 \%$ yield) of polymer 4: $\eta_{\mathrm{idd}}=0.28 \mathrm{dL} / \mathrm{g}$ (c. $0.5 \mathrm{~g} / \mathrm{dL}$ in DMSO at $25^{\circ} \mathrm{C}$ ). ${ }^{1} \mathrm{H}$ NMR (DMSO- $\left.d_{1}\right) \delta 3.56-3.64$ (s. $3 \mathrm{H}, \mathrm{CO}_{2} \mathrm{CH}_{3}$ ), $4.33-4.71$ (d. 8H. $2 \mathrm{Ph}-\mathrm{O}-\mathrm{CH}_{2}-\mathrm{CH}_{-}-\mathrm{O}-$ ). 7.24 (s, 1H, aromatic). 7.42 (s. $1 \mathrm{H}$, aromatic). $7.62-8.03(\mathrm{~m} .5 \mathrm{H}$, aromatic) 8.55 (s. lH. -Ph-CH=). IR (KBr) 2955 (m, C-H). 2224 (m. CN), 1722 (vs. $\mathrm{C}=\mathrm{O}$ ). 1605 (s. $\mathrm{C}=\mathrm{C}$ ) $\mathrm{cm}^{-1}$. Anal. Calcd for $\left(\mathrm{C}_{22} \mathrm{H}_{19} \mathrm{NO}_{8}\right)_{\mathrm{n}}$ : C. $63.16: H, 4.37 ;$ N. 3.20 . Found: C. $63.23:$ H. $4.42 ; \mathrm{N}, 3.25$.

Acknowledgments. This work was supported by the 2008 Inje University research grant.

\section{References}

1. Cho, M. J.; Kim, J. Y.; Kim, J. H.; Lee, S. H.; Dalton, L. R.; Choi, D. H. Bull. Korean Chem. Soc. 2005, 26,77.

2. Lee, C.: Park, S.-K.: Yang, M: Lee, N.-S.: Kim, N. I. Buhl. Korean Chem. Soc. 2007, 28, 447.

3. Yoon, Z. S.; Easwaramoorthi, S.; Kim, D. Bull. Korean Chem. Soc. 2008, 29, 197.

4. Han, K. S.: Park, S. K.: Shim, S. Y.: Tahng, W. S.: Kim, N. I. Bull. Korean Chem. Soc. 1998, 19, 1165

5. Han, K. S.; Park, S. K.; Shim, S. Y.; Lee, Y. S.; Tahng, W. S.; Kim, N. J. Bull. Konean Chem. Soc 1998,19, 1168.

6. Cho, B. R.; Kim, Y. H.: Son, K. W.: Khalil, C.; Kim, Y. H.: Jeon, S.-I. Bull Korean Chem. Soc. 2002. 23, 1253 .

7. Moon, J. R.; Kim, B. S.; Kim, J.-H. Bull. Korean Chem. Soc. 2006, 27,981.

8. Kim, M. H.; Jin, T.-I; Lee, C. T; Kim, N. T.; Park, C. H. Bull. Korean Chem. Soc 2002, 23, 964.

9. Lee, J.-H.: Lee, K.-S. Bull. Korean Chem. Soc. $2000,21,847$.

10. Lee, S.-H.; Kim, Y.-K.; Won, Y.-H. Macrontolecules 1999, 32 , 342

11. Lee, J-Y.: Iung, W-T.: Lee, W-I. Polnm Int. 2006, 55, 248.

12. Lee, J-Y.; Kim, T-H.; Jung, W.-T. Bull. Korean Chem. Soc. $2007,28,329$.

13. Lee, T.-Y.; Kim, T.-H.; Won, D.-S.; Jang, H.-N. Bull. Korean Chent Soc. 2007, 28, 1433.

14. Cisneros, I. I. Appl. Opt 1998, 37, 5262

15. Herman, W. N.; Hayden, L. M. J. Opt. Soc. Am. B 1995, 12, 416. 